\title{
Effectiveness of a 3-month antifalling program in the mobility, balance confidence, and muscle performance of older adults
}

\author{
Rahim Nor ${ }^{1,2}$, Maria Justine ${ }^{1, *}$, Angelbeth Joanny' ${ }^{1}$ Azrul Anuar Zolkafli ${ }^{3}$ \\ ${ }^{1}$ Center for Physiotherapy Studies, Faculty of Health Sciences, Universiti Teknologi MARA Selangor, Puncak Alam Campus, Selangor, Malaysia \\ ${ }^{2}$ Klinik Kesihatan Cheras, Jalan Yaacob Latiff, Kuala Lumpur, Malaysia \\ ${ }^{3}$ Faculty of Sport Science and Coaching, Universiti Pendidikan Sultan Idris, Perak Darul Ridzuan, Malaysia
}

This study determined the effectiveness of a 3-month group-based multicomponent exercise program in the mobility, balance confidence, and muscle performance of older adults. A total of 40 participants (mean age $=70.60 \pm 6.25$ years completed pre- and posttest clinical intervention measures of mobility using the Timed Up and Go (TUG) test, balance confidence using the Activities-specific Balance Confidence scale, upper limb strength (handgrip dynamometer), and lower limb function (30-sec chair rise test). Data were analyzed using paired $t$-test and based on TUG criteria for risk of fall (low- and high-risk groups). Significant improvements were found in all measures (All $P<0.05$ ) following the 3-month program. Measures according to the risk of fall categories were also significantly improved $(P<0.01)$, except the left handgrip strength $(P>0.05)$. The low-risk group showed a higher improvement in mobility $(14.87 \%$ vs. $11.74 \%)$, balance confidence ( $34.21 \%$ vs. $26.08 \%)$, and lower limb function ( $96.87 \%$ vs. $21.20 \%$ ) but was not significantly different from the high-risk group $(P>0.05)$. A group-based multicomponent exercise program benefited the physical functions of older adults at low- or high risk of falls.

Keywords: Balance function, Older adults, Falls, Multicomponent exercise, Physical performance

\section{INTRODUCTION}

A fall, which is defined as an event resulting in a person coming to rest inadvertently on the ground or floor or other low level (World Health Organization, 2021), is a major and serious health issue among the older adults. Each year, at least one third of individuals over the age of 65 years living in communities experience falls, and this proportion increases as age advances (Gamage et al., 2019). The study of Motalebi et al. (2018) on community-dwelling older adults in Malaysia revealed that $18.6 \%$ of such individuals had a history of falls associated with advanced age, especially those aged $75-84$ years and $\geq 85$ years and women. Older adults who experience recurrent falls demonstrate significantly reduced lower extremity strength, dynamic balance, endurance, balance confidence in daily activities, and physical activity levels (Samah et al., 2018). Thus, to prevent fall incidences and optimize their daily functioning, older individuals require effective intervention.

Previous studies suggested that exercise training is the single most effective intervention for improving balance performance and other fall-related physical functions among older adults (Aviles et al., 2019; Halvarsson et al., 2015; Sherrington et al., 2019; Yang et al., 2018). Exercise training for older adults should be adequately long and specifically designed based on individual needs. Longterm training may increase muscle activation and improve coordination through neural adaptation within the central nervous (Krause et al., 2018) or neuromuscular system, which is responsible for coordinating balance performance (Behrens et al., 2017). However, no specific fall prevention program for older adults exists (Shum-
*Corresponding author: Maria Justine (iD https://orcid.org/0000-0002-2412-8653 Centre for Physiotherapy Studies, Faculty of Health Sciences, Universiti Teknologi MARA Selangor, 42300 Puncak Alam, Selangor. Malaysia Email: maria205@uitm.edu.my

Received: July 7, 2021 / Accepted: July 28, 2021
This is an Open Access article distributed under the terms of the Creative Commons Attribution Non-Commercial License (https://creativecommons.org/licenses/by-nc/4.0/) which permits unrestricted non-commercial use, distribution, and reproduction in any medium, provided the original work is properly cited. 
way-Cook et al., 2007; Thompson et al., 2019). Thus, to minimize fall risk, development of a multicomponent exercise training program may be the best approach, as such a program combines several types of exercises, such as strengthening, aerobic, balance, and flexibility exercises. The incorporation of strengthening exercises in a balance training program can increase gait velocity and balance confidence in participants after completing a 5-week training routine (Gillespie et al., 2009). Accordingly, strengthening lower extremities may accelerate the movement of fast-twitch and large muscle fibers, thereby enhancing muscle coordination and the neuromuscular system and leading to improved static and dynamic balance (Paterno et al., 2004).

The purpose of this pretest-posttest intervention study is to determine the effectiveness of a 3-month group-based multicomponent exercise program conducted at a senior citizen center in Cheras, Malaysia, in improving balance and muscle functions in community-dwelling older adults. Specifically, the objectives of this study are (a) to examine the effects of the exercise program on mobility, balance confidence, upper limb strength, and lower limb muscle functions and (b) to compare the effects of the exercise program on mobility, balance confidence, and muscle functions between older adults with high and low fall risk.

\section{MATERIALS AND METHODS}

This study analyzed data from a pretest-posttest intervention community exercise program conducted at a senior citizen center in Cheras, Malaysia, from November 2019 to February 2020. The center provides a venue for community outreach services for older adults by various government agencies and nongovernment organizations. As this center provides a voluntary community service, the number of participants in the study was based on availability. A total of 40 participants completed the 3-month exercise program. The participants who were included in the analysis were registered at the senior citizen center in Cheras, Malaysia. This study included male and female individuals between the ages of 60 and 83 years who completed the three-month program (2-5 sessions a week). In the implementation of the program, older adults diagnosed with a chronic medical illness, such as neurological impairment or cardiac problems, were restricted from participating in the groupbased training. The center's common practice for older adults with chronic diseases participating in the program is the individual approach. Permission to obtain data was given by the director of the center, and the study protocol was approved by the Research Ethics Committee of a university (approval number: REC/05/2021
[UG/MR/437]).

\section{Instrumentation}

\section{Demographic data}

Demographic data such as age (years), ethnicity (Malay/Chinese/ Indian), gender, employment status (working/retired), medical illness (e.g., hypertension and/or diabetes mellitus), and body mass index (BMI) were obtained from the personal file of each participant.

The exercise program outcomes measured before and after 3 months included mobility (balance performance), balance confidence, and muscle performance (handgrip strength and lower limb functions).

\section{Mobility}

Mobility or balance performance was measured using the Timed Up and Go (TUG) test, which aims to determine balance and mobility control during dynamic movement (Sousa and Sampaio, 2005). The TUG test measures the amount of time (in seconds) it takes for a participant to start to stand up from a standard armchair (with a seat height of approximately $46 \mathrm{~cm}$ or 18 in and an arm height of $65 \mathrm{~cm}$ or 25.60 in); walk a distance of $3 \mathrm{~m}$ (approximately 118 in or 10 feet); change direction at the end of the 3-m walk, marked by a cone (turn); head back to the chair; and sit down. After a demonstration by the physiotherapist, the participants were allowed one practice trial. The time it took to complete one attempt was recorded using a second-hand digital watch. The cutoff value for high fall risk is $>13 \mathrm{sec}$ (Belza et al., 2006).

\section{Balance confidence}

Balance confidence was assessed using the Activities-specific Balance Confidence $(\mathrm{ABC})$ scale. The $\mathrm{ABC}$ scale comprises a series of questions assessing subjective fear of falling based on 16 items rated on a scale of 0 to 100 , reflecting balance confidence to perform certain activities (Nilsagård et al., 2012). For each question, the participants were required to indicate their level of confidence in doing a task without losing their balance or stability by choosing one percentage point from the $0 \%-100 \%$ scale. If they did not engage in a certain activity, they were instructed to imagine how relaxed they would be if they engaged in the exercise. If they typically used a walking aid or relied on others for support during training, they were asked to indicate their level of confidence in participating in the exercise with the use of such supports. A score of $<67 \%$ indicated high fall risk. Several studies reported that the $\mathrm{ABC}$ scale demonstrates satisfactory validity and reliability for older adults (Liao et al., 2017) and individuals who suffered from 
a stroke (Tsekoura et al., 2018), while others reported that the ABC scale is the most accurate measure for identifying individuals at risk for multiple falls (Moiz et al., 2017).

\section{Muscle performance}

Handgrip strength was measured to represent upper limb muscle strength. A hand dynamometer was used in this study (Lafayette Instrument J00105 Jamar hydraulic hand dynamometer), which is a gold standard tool for handgrip strength assessment, with excellent validity and reliability in clinical and research settings (Guderian et al., 2013). The participants, in a sitting position, were asked to hold the dynamometer in their hand at the second bar, with adducted shoulders, elbow flexed to 90 degrees, and forearm in a neutral position with slight wrist extension. The participants were instructed to use full isometric effort to squeeze the dynamometer and sustain their grip for 2 to $5 \mathrm{sec}$. The physiotherapist demonstrated the procedure, and the participants performed three trials for each hand, with a 60 -sec rest interval between trials. The average of the three trials was recorded as the final score. The cutoff point for handgrip strength is $28 \mathrm{~kg}$ for men and $16 \mathrm{~kg}$ for women (Yoo et al., 2017).

The 30-sec chair stand test was used to measure lower limb functions (Jones et al., 1999; Nilsagård et al., 2012). For the test, the participants were instructed to sit on a secure straight-backed chair (with a height of approximately 17 in) with their arms folded over their chest. Next, the participants were instructed to rise to their full height then return to a sitting position, and repeat the movement as many times as possible within $30 \mathrm{sec}$. The participants completed a practice trial of two repetitions following the physiotherapist's demonstration, followed by one 30-sec test trial. The number of stand-sit exercises performed within $30 \mathrm{sec}$ was recorded as the final score.

\section{Exercise program}

The training program designed for the participants included multicomponent exercises, that is, a combination of strength, aerobic, balance, and flexibility exercises. Several studies found that multicomponent exercises are safe and effective for older individuals living in a community (Gonçalves et al., 2021; Suzuki et al., 2013) or institution (Justine and Hamid, 2010). Table 1 summa-

Table 1. The exercise program

\begin{tabular}{|c|c|}
\hline Exercise component & Movement \\
\hline $\begin{array}{l}\text { Warm-up } \\
\text { Duration: } 10 \text { min } \\
\text { Aerobic exercise } \\
\text { Frequency: } 5 \text { days/wk } \\
\text { Intensity: moderate: on a scale of 0-10 for physical exercise, 5-6 for aerobic exercise } \\
\text { with moderate intensity, 7-8 for an aerobic workout with a strong intensity } \\
\text { Times: } 30-60 \text { min/session } \\
\text { Types: "Chairobic" exercises, brisk walk } \\
\text { Progression: increase distance of the walk }\end{array}$ & $\begin{array}{l}\text { - Begin with a breathing exercise } \\
\text { - Active full range of motion movement: neck, shoulder, wrist, trunk, hip, knee, and } \\
\text { ankle. } \\
\text { - Marching in place, alternate toe touches to front, alternate heel touches, and } \\
\text { alternate toe touches to sides, alternate heel touches to sides, alternate kicks, } \\
\text { alternate } \\
\text { - Knee lifts, and alternate double knee lifts, side toe tap, heel raise } \\
\text { - All movements were incorporated with upper limb movement, such as clapping, } \\
\text { elbow flexion and extension, and shoulder abduction/flexion/extension/cross } \\
\text { adduction }\end{array}$ \\
\hline $\begin{array}{l}\text { Strengthening exercise } \\
\text { Frequency: } 2 \text { days/wk } \\
\text { Intensity: moderate: } 5-6 \text { for resistance with moderate intensity. } \\
\text { Times: } 8 \text { resistance exercise } 1-3 \text { set } 10 \text { repetition each set } \\
\text { Types: elastic band exercise in sitting and standing } \\
\text { Progression: increase number of sets }\end{array}$ & $\begin{array}{l}\text { - Sitting: shoulder flexion, abduction, adduction, internal rotation, external rotation, } \\
\text { biceps curl, and arm horizontal abduction with an elastic band (upper limb) double } \\
\text { hip abduction and flexion with an elastic band tied at mid-thigh (lower limb) } \\
\text { - Standing holding a chair and performing plantar flexion, knee flexion, hip flexion, } \\
\text { knee extension, squatting, hip extension, and side leg raise; sitting to standing } \\
\text { elastic band at mid-thigh hip flexion, extension, abduction (lower limb) }\end{array}$ \\
\hline $\begin{array}{l}\text { Flexibility exercise } \\
\text { Frequency: } 2 \text { days/wk } \\
\text { Intensity: moderate } \\
\text { Times } 10 \text { min with } 15 \text {-sec hold static stretching } \\
\text { Types: general upper and lower limb }\end{array}$ & $\begin{array}{l}\text { - Shoulder flexion with arm touching the arm: hand pushing up } \\
\text { - Hamstring stretch: knee extension with hands trying to reach toes } \\
\text { - Trunk side bending, calves stretch, and shoulder retraction } \\
\text { - Sitting: wrist flexor and extensor stretch, double hip abduction } \\
\text { - Neck side flexion, neck extension, and neck rotation to the left and right }\end{array}$ \\
\hline $\begin{array}{l}\text { Balance exercise } \\
\text { Frequency: } 2 \text { days/wk } \\
\text { Intensity: moderate } \\
\text { Times: } 10 \text {-min static and dynamic balance } \\
\text { Types: static and dynamic }\end{array}$ & $\begin{array}{l}\text { - Standing: lifting leg forward, backward, sideways, tandem walking forward and } \\
\text { backward. Taping balloon in standing } \\
\text { - Open eyes and close eyes. }\end{array}$ \\
\hline $\begin{array}{l}\text { Cool-down session } \\
\text { Duration: } 10 \text { min }\end{array}$ & $\begin{array}{l}\text { - Range of motion exercises for the neck, shoulder, wrist, trunk, hip, knee, and ankle } \\
\text { - Exercise is ended with a breathing exercise }\end{array}$ \\
\hline
\end{tabular}


rizes the exercise training program implemented for the participants.

\section{Data analysis}

Data from the assessment forms were processed and analyzed using IBM SPSS Statistics ver. 20.0 (IBM Co., Armonk, NY, USA). The participants' characteristics were described using frequencies, percentages, means, and standard deviations. The Shapiro-Wilk test indicated that the pre- and posttest data were normally distributed, thus, the paired sample $t$-test was used to determine the significance differences in the outcomes for the one-group comparison. The 50 th percentile $(13 \mathrm{sec}$ ) of the TUG test score was used as the cutoff point to divide the participants into low and high fall risk categories. The participants who scored $<13$ sec were classified under the low-risk category, whereas those who scored $13 \mathrm{sec}$ or above were classified under the high-risk category. The comparison within-group for each measure was analyzed using the Wilcoxon sign-ranked test, while, the Mann-Whitney $U$-test was used to compare differences between groups. The differences in the percentage of changes (pre- and postintervention) were calculated according to the following formula: (posttest mean value-pretest mean value/pretest mean value $\times 100$ ), for each fall risk category and presented in a table. Significance level was set at $P<0.05$.

\section{RESULTS}

A total of 40 participants were included in the analysis. The characteristics of the participants are presented in Table 2. The mean age of the participants was $70.60 \pm 6.25$ years. The majority of the participants were female, between the ages of 67 and 75 years, had a normal BMI, Chinese, retired, had hypertension, and had high risk for falls.

Table 3 shows the results of the pretest and posttest based on the paired $t$-test. The results revealed a significant improvement in mobility $(P<0.001)$, balance confidence $(P<0.001)$, left $(P=0.035)$, and right $(P<0.001)$ upper limb strength, and lower limb functions $(P<0.001)$ in all the participants.

Table 4 reports the ddifferences for within and between groups and the percentage of change of each variable. The low-risk group (vs. high-risk group) showed a higher improvement in mobility

Table 2. Characteristics of participants ( $N=40)$

\begin{tabular}{|c|c|c|}
\hline Variable & №. (\%) & Mean \pm SD (range) \\
\hline Gender & & - \\
\hline Male & $10(25)$ & \\
\hline Female & $30(75)$ & \\
\hline Age (yr) & & $70.60 \pm 6.25(60-83)$ \\
\hline $60-66$ & $11(35)$ & \\
\hline $67-75$ & $18(45)$ & \\
\hline$\geq 76$ & $12(20)$ & \\
\hline Body mass index (kg/m²) & & $24.15 \pm 1.76(21-28)$ \\
\hline Normal (21-24) & $28(70)$ & \\
\hline Overweight (25-28) & $12(30)$ & \\
\hline \multicolumn{3}{|l|}{ Ethnicity } \\
\hline Malay & $15(37.50)$ & \\
\hline Chinese & $24(60)$ & \\
\hline Indian & $1(2.5)$ & \\
\hline \multicolumn{3}{|l|}{ Occupation } \\
\hline Retired & $36(90)$ & \\
\hline Working & $4(10)$ & \\
\hline \multicolumn{3}{|l|}{ Hypertension } \\
\hline Yes & $24(60)$ & \\
\hline No & $16(40)$ & \\
\hline \multicolumn{3}{|l|}{ Diabetes mellitus } \\
\hline Yes & $14(35)$ & \\
\hline No & $26(65)$ & \\
\hline Risk of falls (based on TUG) & & $14.74 \pm 3.94(8-27)$ \\
\hline Low risk ( $\leq 13 \mathrm{sec}$ ) & $19(47.50)$ & \\
\hline High risk (> $13 \mathrm{sec}$ ) & $21(52.50)$ & \\
\hline
\end{tabular}

SD, standard deviation; TUG, Timed Up and Go test.

Table 3. Pretest-posttest analysis using paired $t$-test $(\mathrm{N}=40)$

\begin{tabular}{|c|c|c|c|c|c|c|}
\hline Variable & Pretest & Posttest & $\%$ Change & $95 \% \mathrm{Cl}$ & $t \mathrm{df}$ & $P$-value \\
\hline Mobility (TUG) & $14.74 \pm 3.94$ & $12.84 \pm 3.66$ & 12.89 & $1.56-2.23$ & 11.46 & $0.001^{* *}$ \\
\hline Balance confidence (ABC scale) & $7.05 \pm 0.88$ & $8.05 \pm 0.85$ & 14.18 & -1.10 to -0.90 & -19.75 & $0.001^{* *}$ \\
\hline Left upper limb strength (handgrip) & $19.95 \pm 4.70$ & $20.85 \pm 5.18$ & 4.51 & -1.73 to -0.07 & -2.19 & $0.035^{*}$ \\
\hline Right upper limb strength (handgrip) & $22.48 \pm 5.48$ & $23.78 \pm 5.73$ & 5.78 & -1.84 to 0.76 & -4.89 & $0.001^{*}$ \\
\hline Lower limb function (30 CRT) & $9.03 \pm 2.47$ & $10.48 \pm 2.41$ & 16.06 & -1.86 to -1.04 & -7.16 & $0.001^{*}$ \\
\hline
\end{tabular}

Values are presented as mean \pm standard deviation.

$\mathrm{Cl}$, confidence interval; df, degrees of freedom; TUG, Timed Up and Go test; ABC, Activities-specific Balance Confidence; 30 CRT, 30-seond chair rise test.

${ }^{*} P<0.05$ and ${ }^{* *} P<0.01$, significant difference at based on paired $t$-test. 
Table 4. Differences (post-pre intervention) for within and between groups

\begin{tabular}{|c|c|c|c|c|c|c|c|}
\hline \multirow{2}{*}{ Variable } & \multicolumn{3}{|c|}{ High risk ( $n=21)$} & \multicolumn{3}{|c|}{ Low risk $(n=19)$} & \multirow{2}{*}{$\begin{array}{l}\text { Between-group } \\
\text { differences } P \text {-value }\end{array}$} \\
\hline & Pretest & Posttest & $\% \Delta(P$-value $)$ & Pretest & Posttest & $\% \Delta(P$-value $)$ & \\
\hline Mobility & $17.12 \pm 3.73$ & $15.11 \pm 3.23$ & $11.74\left(0.001^{*}\right)$ & $11.83 \pm 1.46$ & $10.07 \pm 1.74$ & $14.87\left(0.001^{*}\right)$ & 0.104 \\
\hline Balance confidence & $3.45 \pm 0.80$ & $2.55 \pm 0.74$ & $26.08\left(0.001^{*}\right)$ & $2.28 \pm 0.46$ & $1.50 \pm 0.51$ & $34.21\left(0.001^{*}\right)$ & 0.263 \\
\hline Left handgrip strength & $19.09 \pm 4.13$ & $20.36 \pm 4.56$ & $6.65\left(0.002^{*}\right)$ & $21.00 \pm 5.24$ & $21.44 \pm 5.93$ & $2.10\left(0.151^{*}\right)$ & 0.246 \\
\hline Right handgrip strength & $21.86 \pm 5.09$ & $23.14 \pm .37$ & $5.85\left(0.005^{*}\right)$ & $23.22 \pm 5.99$ & $24.56 \pm 6.20$ & $5.77\left(0.010^{*}\right)$ & 0.494 \\
\hline Lower limb function & $7.50 \pm 1.71$ & $9.09 \pm 2.04$ & $21.20\left(0.001^{*}\right)$ & $10.89 \pm 1.94$ & $21.44 \pm 5.93$ & $96.87\left(0.002^{*}\right)$ & 0.198 \\
\hline
\end{tabular}

Values are presented as mean \pm standard deviation.

The within-group differences were analyzed using the Wilcoxon-signed rank test. The percentage differences in each variable (pre- and postintervention) were calculated according to the following formula: (posttest mean value-pretest mean value/pretest mean value) $\times 100$. The between-group differences were examined using the Mann-Whitney U-test.

${ }^{*} P<0.05$, significant difference.

( $14.87 \%$ vs. $11.74 \%)$, balance confidence $(34.21 \%$ vs. $26.08 \%)$, and lower limb functions $(96.87 \%$ vs. $21.20 \%)$, whereas the highrisk group (vs. low-risk group) showed a higher improvement in left ( $6.65 \%$ vs. $2.10 \%)$ and right (5.85\% vs. $5.77 \%)$ upper limb strength. All comparisons within-group were significantly different (all $P<0.05)$ except for the left handgrip in the low-risk group. The results of the comparisons between groups indicated no significant different (all $P>0.05$ ) for all measures.

\section{DISCUSSION}

Generally, the program was deemed beneficial in improving the physical functions of the participants. The findings of this study may support the need of older adults residing in a community to be involved in activities organized by a senior center as part of the government's efforts to promote active aging in the community.

The findings also provided preliminary data showing that a supervised group-based exercise program was safe and potentially influential, as no adverse events among the participants were reported. A previous study on group-based activity and home-based exercise revealed that 15 of the 17 variables improved after a 12-week intervention and suggested that such types of programs may provide positive feedback and be economical for older adults (Tsekoura et al., 2018). Furthermore, a center-based program could inspire participants effectively through excellent supervision, as instructors' encouragement and input will allow learners to evaluate their development, which may serve as a motivational enhancer (Farrance et al., 2016). Moreover, a group-based program was reported to promote group adhesion and enhance psychological wellbeing and socialization (Kanamori et al., 2015; Mehra et al., 2016).

The data analyzed in this study were obtained from the partici- pants after their completion of the 12-week training program, which is an ideal duration for observing physiological improvements. A previous study conducted for 12 weeks revealed improvements in muscle power, speed, and agility as well as in glucose, insulin, total cholesterol, triglyceride, vitamin D3, and C-reactive protein levels in older patients in long-term healthcare facilities who suffered from a frailty disorder (Ferreira et al., 2018). Another study showed that a 12-week resistance exercise program can positively impact cellular senescence and improve mitochondrial-drying protein deficiency and enzyme-related protein levels (HooshmandMoghadam et al., 2020), which may explain improvements in muscle strength and functions.

In this current study, 22 participants were categorized as high risk for falls, as their TUG score was $>13 \mathrm{sec}$, whereas 18 participants were categorized as low risk for falls $(<13 \mathrm{sec})$. Hence, further analyses were conducted to compare the improvements between the two fall risk groups.

The analysis showed a significant improvement in mobility of $12.89 \%(P<0.01)$ for all the participants following their completion of the program. The findings supported those of previous studies showing that an exercise program consisting of balanced components and different types of exercises, such as strengthening (Hallage et al., 2010; Krause et al., 2018) and step-aerobic exercises, can improve dynamic balance (Hallage et al., 2010; Seguin et al., 2012). Furthermore, exercise prescriptions, as employed in this current program following the recommendation of the American College of Sports Medicine (Nelson et al., 2007), should include strength, balance, aerobic, and flexibility training.

The analysis on mobility based on fall risk showed that improvement was higher in the low-risk group (14.87\%) compared with the low-risk group (11.74\%). Older adults with low fall risk may have satisfactory mobility, whereas those categorized as high risk 
for falls may be frail, as indicated by their low lower limb function score and considerable time to complete the TUG test at the beginning of the program. A previous study emphasized that poor balance in frail older individuals is associated with fear of falling (Kumar et al., 2008), whereas intrinsic factors such as medical illness, medication, balance, and gait problems can also reduce balance performance (Gamage et al., 2019).

A previous study found that fear of falling may lead to reduced balance confidence and suggested that people with diminished confidence have deteriorated balance and fear that their balance will be further reduced (Ahn and Kim, 2015). Fear of falling is not necessarily present in older individuals with a history of falls and can be present in older individuals without such a history (Kumar et al., 2008). As hypothesized, after completing the exercise program, the participants showed a significant improvement in their balance confidence signifying their level of fear of falling, as one of the outcome measures in this study, which is consistent with the findings of other studies (Aibar-Almazán et al., 2019; Smulders et al., 2010). Accordingly, people with low balance confidence can avoid falls by restricting their involvement in activities despite having impaired balance or being at risk for falls (Cho et al., 2012). Meanwhile, the percentage of changes in the low and high fall risk groups was $34.21 \%$ and $26.08 \%$, respectively, thereby indicating that the low-risk group showed a higher improvement than the high-risk group. This result is similar to that of previous research revealing a considerable improvement in nonfallers compared with fallers in terms of their level of confidence (Moiz et al., 2017).

Grip strength can reflect an individual's overall muscle strength and functional ability (Guderian et al., 2013). Moreover, grip strength is typically used as a diagnostic method for assessing early vulnerability symptoms in aging individuals, as the aging-induced weakening of grip strength may contribute to weak bimanual coordination among older adults (Yang et al., 2018). In this study, following their completion of the program, the participants exhibited a significant improvement in their grip strength for both hands $(P<0.05)$, with a slightly higher percentage for the right hand $(5.78 \%)$ compared with the left hand (4.51\%). A previous study showed a significant improvement in the participants' dominant hand compared with their nondominant hand (Incel et al., 2002; Oppewal et al., 2013; Yoo et al., 2017). We believe that most of the participants in this current study were right-hand dominant. The literature suggested that an often-used general rule indicates that the dominant hand is $10 \%$ stronger than the nondominant hand (Incel et al., 2002).
In terms of the current exercise program, the addition of resistance training using elastic bands may have enhanced the participants' upper limb strength (Liao et al., 2017). The use of elastic bands to provide resistance during exercise for older adults, especially those who are frail, is considered safe and practical (Hofmann et al., 2016) and regularly employed in clinical settings (Yasuda et al., 2015). The current study also showed that the high-risk group demonstrated a slight improvement in the left side $(6.65 \%)$ as well as the low-risk group (2.21\%). Meanwhile, in the right side, the high-risk group showed an improvement of $5.85 \%$, whereas the low-risk group exhibited an improvement of approximately $5.77 \%$, which is nearly similar to the result of the high-risk group. Regardless of these results, the high-risk group exhibited better improvement in upper limb strength compared with the low-risk group. This finding is inconsistent with that of a previous report revealing no significant improvement in the handgrip strength of the faller group following intervention (Prata and Scheicher, 2015). Moreover, it was argued that the nondominant hand may have substantial grip strength, thereby showing that neither the dominant nor nondominant hand can be classified as the stronger hand (Oppewal et al., 2013).

Regarding the effect of the exercise program on lower limb functions, our findings showed a significant improvement of $16.06 \%$ $(P<0.01)$, which is consistent with the results of a previous study with participants in their 60s, 70s, and 80s (Rikli and Jones, 2013). The current study included a 30-sec chair stand test to determine lower limb functions in terms of endurance and strength related to fall risk. Deteriorated lower limb functions, specifically, poor walking skills, are essential risk factors correlated with falls among older adults (Morita et al., 2005). A previous study showed that lower limb strength is a significant factor for maintaining functions in older adults (Cebolla et al., 2015). In addition, the number of falls increases by $35 \%$ to $40 \%$ among individuals aged 60 years mainly owing to reduced muscle strength and balance (Hornbrook et al., 1994). A literature also provided evidence showing that the absence of physical activity can lead to the weakening of lower limbs and loss of balance, which are essential precursors of falls among older adults residing in a community (Simpson et al., 2014). The exercise program conducted in this study included exercises for the general strengthening of lower limbs, such as squatting and sit-to-stand exercises and resistance band training, which may have contributed to the considerable improvement in lower limb functions, thereby supporting the recommendation of a previous study (Tsekoura et al., 2018). The effectiveness of elastic bands in resistance training was proven to lead to a significant improvement 
in lower limb functions, especially leg strength (Motalebi et al., 2018).

In comparing the two fall risk categories, the percentage of changes was higher in the low-risk group $(96.87 \%)$ compared with the high-risk group (21.20\%). This finding is consistent with that of a previous study reporting that fallers had substantially fewer repetitions than nonfallers in the 30-sec chair stand test (Roongbenjawan and Siriphorn, 2020). It was also suggested that adding resistance training to an exercise program can significantly improve the muscle strength of frail older individuals (Phu et al., 2015).

In conclusion, the findings of this study indicated that after 3 months of participation in a group-based exercise program, improvements in mobility, balance confidence, upper limb strength, and lower limb functions were noted in the participants regardless of their level of risk for falls. An exercise program combining multicomponent exercise elements, such as strength, aerobic, balance, and flexibility training, and supervised by a physiotherapist may be safe for community-dwelling older adults.

This study has several limitations. First, the findings cannot be generalized to other programs or populations, as the study was conducted in a center for older adults involving groups and the supervision of a physiotherapist, who could include fun and motivational elements in the program. Second, the male and female participants were placed in the same group for the analysis, which was unavoidable owing to the small number of male participants.

\section{CONFLICT OF INTEREST}

No potential conflict of interest relevant to this article was reported.

\section{ACKNOWLEDGMENTS}

The authors wish to thank Universiti Teknologi MARA (UiTM) for supporting the publication of this study through the GERAN PENYELIDIKAN KHAS [Project Code: 600-U/GPK 5/3 (073/ 2020)].

\section{REFERENCES}

Ahn N, Kim K. Effects of an elastic band resistance exercise program on lower extremity muscle strength and gait ability in patients with $\mathrm{Alz}$ heimer's disease. J Phys Ther Sci 2015;27:1953-1955.

Aibar-Almazán A, Martínez-Amat A, Cruz-Díaz D, De la Torre-Cruz MJ, Jiménez-García JD, Zagalaz-Anula N, Pérez-Herrezuelo I, Hita-Con- treras F. Effects of Pilates on fall risk factors in community-dwelling elderly women: a randomized, controlled trial. Eur J Sport Sci 2019; 19:1386-1394.

Aviles J, Allin LJ, Alexander NB, Van Mullekom J, Nussbaum MA, Madigan ML. Comparison of treadmill trip-like training versus Tai Chi to improve reactive balance among independent older adult residents of senior housing: a pilot controlled trial. J Gerontol A Biol Sci Med Sci 2019;74:1497-1503.

Behrens M, Müller K, Kilb JI, Schleese L, Herlyn PK, Bruhn S, Mittlmeier T, Schober HC, Fischer DC. Modified step aerobics training and neuromuscular function in osteoporotic patients: a randomized controlled pilot study. Arch Orthop Trauma Surg 2017;137:195-207.

Belza B, Shumway-Cook A, Phelan EA, Williams B, Snyder SJ, LoGerfo JP. The effects of a community-based exercise program on function and health in older adults: the EnhanceFitness Program. J Appl Gerontol 2006;25:291-306.

Cebolla EC, Rodacki AL, Bento PC. Balance, gait, functionality and strength: comparison between elderly fallers and non-fallers. Braz J Phys Ther 2015;19:146-151.

Cho KH, Bok SK, Kim YJ, Hwang SL. Effect of lower limb strength on falls and balance of the elderly. Ann Rehabil Med 2012;36:386-393.

Farrance C, Tsofliou F, Clark C. Adherence to community based group exercise interventions for older people: a mixed-methods systematic review. Prev Med 2016;87:155-166.

Ferreira CB, Teixeira PD, Alves dos Santos G, Dantas Maya AT, Americano do Brasil P, Souza VC, Córdova C, Ferreira AP, Lima RM, Nóbrega OD. Effects of a 12-week exercise training program on physical function in institutionalized frail elderly. J Aging Res 2018;2018:7218102.

Gamage N, Rathnayake N, Alwis G. Prevalence and associated risk factors of falls among rural community-dwelling older people: a crosssectional study from southern Sri Lanka. Curr Gerontol Geriatr Res 2019;2019:2370796.

Gillespie LD, Gillespie WJ, Robertson MC, Lamb SE, Cumming RG, Rowe $\mathrm{BH}$. Interventions for preventing falls in elderly people. Cochrane Database Syst Rev 2003;(4):CD000340.

Gonçalves AK, Griebler EM, da Silva WA, Sant DP, da Silva PC, Possamai VD, Martins VF. Does a multicomponent exercise program improve physical fitness in older adults? findings from a 5-year longitudinal study. J Aging Phys Act 2021 Mar 24:1-8. https://doi.org/10.1123/japa. 2020-0070 [Epub].

Guderian B, Johnson A, Mathiowetz V. Impact of exercise frequency on hand strength of the elderly. Phys Occup Ther Geriatr 2013;31:268-279.

Hallage T, Krause MP, Haile L, Miculis CP, Nagle EF, Reis RS, Da Silva SG.

The effects of 12 weeks of step aerobics training on functional fitness of elderly women. J Strength Cond Res 2010;24:2261-2266. 
Halvarsson A, Franzén E, Ståhle A. Balance training with multi-task exercises improves fall-related self-efficacy, gait, balance performance and physical function in older adults with osteoporosis: a randomized controlled trial. Clin Rehabil 2015;29:365-375.

Hofmann M, Schober-Halper B, Oesen S, Franzke B, Tschan H, Bachl N, Strasser EM, Quittan M, Wagner KH, Wessner B. Effects of elastic band resistance training and nutritional supplementation on muscle quality and circulating muscle growth and degradation factors of institutionalized elderly women: the Vienna Active Ageing Study (VAAS). Eur J Appl Physiol 2016;116:885-897.

Hooshmand-Moghadam B, Eskandari M, Golestani F, Rezae S, Mahmoudi N, Gaeini AA. The effect of 12-week resistance exercise training on serum levels of cellular aging process parameters in elderly men. Exp Gerontol 2020;141:111090.

Hornbrook MC, Stevens VJ, Wingfield DJ, Hollis JF, Greenlick MR, Ory MG. Preventing falls among community-dwelling older persons: results from a randomized trial. Gerontologist 1994;34:16-23.

Incel NA, Ceceli E, Durukan PB, Erdem HR, Yorgancioglu ZR. Grip strength: effect of hand dominance. Singapore Med J 2002;43:234-237.

Jones CJ, Rikli RE, Beam WC. A 30-s chair-stand test as a measure of lower body strength in community-residing older adults. Res Q Exerc Sport 1999;70:113-119.

Justine M, Hamid TA. Effects on depression and quality of life. J Gerontol Nurs 2010;36:32-41.

Kanamori S, Takamiya T, Inoue S. Group exercise for adults and elderly: determinants of participation in group exercise and its associations with health outcome. J Phys Fit Sports Med 2015;4:315-320.

Krause A, Freyler K, Gollhofer A, Stocker T, Brüderlin U, Colin R, Töpfer $\mathrm{H}$, Ritzmann R. Neuromuscular and kinematic adaptation in response to reactive balance training - a randomized controlled study regarding fall prevention. Front Physiol 2018;9:1075.

Kumar S, Vendhan GV, Awasthi S, Tiwari M, Sharma VP. Relationship between fear of falling, balance impairment and functional mobility in community dwelling elderly. Indian J Phys Med Rehabil 2008;19:48-52.

Liao CD, Tsauo JY, Lin LF, Huang SW, Ku JW, Chou LC, Liou TH. Effects of elastic resistance exercise on body composition and physical capacity in older women with sarcopenic obesity. Medicine 2017;96:e7115.

Mehra S, Dadema T, Kröse BJ, Visser B, Engelbert RH, Van Den Helder J, Weijs PJ. Attitudes of older adults in a group-based exercise program toward a blended intervention; a focus-group study. Front psychol 2016;7:1827.

Moiz JA, Bansal V, Noohu MM, Gaur SN, Hussain ME, Anwer S, Alghadir A. Activities-specific balance confidence scale for predicting future falls in Indian older adults. Clin Interv Aging 2017;12:645-651.

Morita M, Takamura N, Kusano Y, Abe Y, Moji K, Takemoto TI, Aoyagi K.
Relationship between falls and physical performance measures among community-dwelling elderly women in Japan. Aging Clin Exp Res 2005;17:211-216.

Motalebi SA, Cheong LS, Iranagh JA, Mohammadi F. Effect of low-cost resistance training on lower-limb strength and balance in institutionalized seniors. Exp Aging Res 2018;44:48-61.

Nelson ME, Rejeski WJ, Blair SN, Duncan PW, Judge JO, King AC, Macera CA, Castaneda-Sceppa C. Physical activity and public health in older adults: recommendation from the American College of Sports Medicine and the American Heart Association. Circulation 2007;116:10941105.

Nilsagård Y, Carling A, Forsberg A. Activities-specific balance confidence in people with multiple sclerosis. Mult Scler Int 2012;2012:613925.

Oppewal A, Hilgenkamp TI, van Wijck R, Evenhuis HM. The effect of handedness on grip strength in older adults with intellectual disabilities. Res Dev Disabil 2013;34:1623-1629.

Paterno MV, Myer GD, Ford KR, Hewett TE. Neuromuscular training improves single-limb stability in young female athletes. J Orthop Sports Phys Ther 2004;34:305-316.

Phu S, Boersma D, Duque G. Exercise and sarcopenia. J Clin Densitom 2015;18:488-492.

Prata MG, Scheicher ME. Effects of strength and balance training on the mobility, fear of falling and grip strength of elderly female fallers. J Bodyw Mov Ther 2015;19:646-650.

Rikli RE, Jones CJ. Development and validation of criterion-referenced clinically relevant fitness standards for maintaining physical independence in later years. Gerontologist 2013;53:255-267.

Roongbenjawan N, Siriphorn A. Accuracy of modified 30-s chair-stand test for predicting falls in older adults. Ann Phys Rehabil Med 2020;63: 309-315.

Samah ZA, Singh DK, Murukesu RR, Shahar S, Nordin NA, Omar MA, Chin AV. Discriminative and predictive ability of physical performance measures in identifying fall risk among older adults. Sains Malaysiana 2018;47:2769-2776.

Seguin RA, Heidkamp-Young E, Kuder J, Nelson ME. Improved physical fitness among older female participants in a nationally disseminated, community-based exercise program. Health Educ Behav 2012;39:183190.

Sherrington C, Fairhall NJ, Wallbank GK, Tiedemann A, Michaleff ZA, Howard K, Clemson L, Hopewell S, Lamb SE. Exercise for preventing falls in older people living in the community. Cochrane Database Syst Rev 2019;1:CD012424.

Shumway-Cook A, Silver IF, LeMier M, York S, Cummings P, Koepsell TD. Effectiveness of a community-based multifactorial intervention on falls and fall risk factors in community-living older adults: a ran- 
domized, controlled trial. J Gerontol A Biol Sci Med Sci 2007;62:14201427.

Simpson AH, Hamilton DF, Beard DJ, Barker KL, Wilton T, Hutchison JD, Tuck C, Stoddard A, Macfarlane GJ, Murray GD. Targeted rehabilitation to improve outcome after total knee replacement (TRIO): study protocol for a randomised controlled trial. Trials 2014;15:44.

Smulders E, Weerdesteyn V, Groen BE, Duysens J, Eijsbouts A, Laan R, Van Lankveld W. Efficacy of a short multidisciplinary falls prevention program for elderly persons with osteoporosis and a fall history: a randomized controlled trial. Arch Phys Med Rehabil 2010;91:17051711.

Sousa N, Sampaio J. Effects of progressive strength training on the performance of the Functional Reach Test and the Timed Get-Up-and-Go Test in an elderly population from the rural north of Portugal. Am J Hum Biol 2005;17:746-751.

Suzuki T, Shimada H, Makizako H, Doi T, Yoshida D, Ito K, Shimokata H, Washimi Y, Endo H, Kato T. A randomized controlled trial of multicomponent exercise in older adults with mild cognitive impairment. PLoS One 2013;8:e61483.

Thompson CJ, Holskey TH, Wallenrod S, Simunovich S, Corn R. Effec- tiveness of a fall prevention exercise program on falls risk in community-dwelling older adults. Transl J Am Coll Sports Med 2019;4:16-22.

Tsekoura M, Billis E, Tsepis E, Dimitriadis Z, Matzaroglou C, Tyllianakis M, Panagiotopoulos E, Gliatis J. The effects of group and home-based exercise programs in elderly with sarcopenia: a randomized controlled trial. J Clin Med 2018;7:480.

World Health Organization. Falls [Internet]. Geneva (Switzerland): World Health Organization; 2021 [cited 2021 Jul 21]. Available from: https:// www.who.int/news-room/fact-sheets/detail/falls.

Yang NP, Hsu NW, Lin CH, Chen HC, Tsao HM, Lo SS, Chou P. Relationship between muscle strength and fall episodes among the elderly: the Yilan study, Taiwan. BMC Geriatr 2018;18:90.

Yasuda T, Fukumura K, Uchida Y, Koshi H, Iida H, Masamune K, Yamasoba T, Sato Y, Nakajima T. Effects of low-load, elastic band resistance training combined with blood flow restriction on muscle size and arterial stiffness in older adults. J Gerontol A Biol Sci Med Sci 2015;70:950-958.

Yoo JI, Choi H, Ha YC. Mean hand grip strength and cut-off value for sarcopenia in Korean adults using KNHANES VI. J Korean Med Sci 2017; 32:868-872 